\title{
Anxiety- and Depression-Like Behavior and Impaired Neurogenesis Evoked by Peripheral Neuropathy Persist following Resolution of Prolonged Tactile Hypersensitivity
}

\author{
Eugene L. Dimitrov, ${ }^{1}$ Mumeko C. Tsuda, ${ }^{1}$ Heather A. Cameron, ${ }^{2}$ and Ted B. Usdin ${ }^{1}$ \\ ${ }^{1}$ Section on Fundamental Neuroscience and ${ }^{2}$ Unit on Neuroplasticity, National Institute of Mental Health, Bethesda, Maryland 20892
}

Pain and depression are frequently associated with and often persist after resolution of an initial injury. Identifying the extent to which depression remains causally associated with ongoing physical discomfort during chronic pain, or becomes independent of it, is an important problem for basic neuroscience and psychiatry. Difficulty in distinguishing between effects of ongoing aversive sensory input and its long-term consequences is a significant roadblock, especially in animal models. To address this relationship between localized physical discomfort and its more global consequences, we investigated cellular and behavioral changes during and after reversing a mouse model of neuropathic pain. Tactile allodynia produced by placing a plastic cuff around the sciatic nerve resolved within several days when the cuff was removed. In contrast, the changes in elevated 0-maze, forced-swim, Y-maze spontaneous alternation and novel-object recognition test performance that developed after nerve cuff placement remained for at least 3 weeks after the nerve cuffs were removed, or 10-15 d following complete normalization of mechanical sensitivity. Hippocampal neurogenesis, measured by doublecortin and proliferating cell nuclear antigen expression, was also suppressed after nerve cuff placement and remained suppressed 3 weeks after cuff removal. FosB expression was elevated in the central nucleus of the amygdala and spinal cord dorsal horn only in mice with ongoing allodynia. In contrast, FosB remained elevated in the basolateral amygdala of mice with resolved nociception and persisting behavioral effects. These observations suggest that different processes control tactile hypersensitivity and the behavioral changes and impaired neurogenesis that are associated with neuropathic allodynia.

Key words: adult neurogenesis; chronic pain; depression; neuropathic pain; reversible neuropathic injury; sciatic nerve

\section{Introduction}

Clinical observations and epidemiological studies show frequent association of chronic pain with psychiatric disorders, including a high prevalence of major depression among pain clinic patients and a high lifetime comorbidity between neuropathic pain and mood disorders (Knaster et al., 2012; Radat et al., 2013). Despite these well established associations, the extent to which depression and chronic pain contribute to the development or maintenance of the other is not clear. The combination of chronic pain and an anxiety or mood disorder is very difficult to treat, and there is little understanding of the pathophysiological mechanisms that link persistent pain and depressed mood, making investigation of their relationship an important research problem.

Received Jan. 22, 2014; revised July 26, 2014; accepted July 29, 2014.

Author contributions: E.L.D. and T.B.U. designed research; E.L.D., M.C.T., and T.B.U. performed research; E.L.D., H.A.C., and T.B.U. analyzed data; E.L.D., H.A.C., and T.B.U. wrote the paper.

This project was supported by the Intramural Research Program of the National Institutes of Health-National Institute of Mental Health. Technical support was provided by Jonathan Kuo. Janice Urban generously provided facilities for some of the work.

The authors declare no competing financial interests.

Correspondence should be addressed to Ted B. Usdin, Section on Fundamental Neuroscience, National Institute of Mental Health, Building 35, Room 1B-215, 35 Convent Drive, Bethesda, MD 20892. E-mail: usdint@mail.nih.gov.

E.L. Dimitrov's present address: Department of Physiology and Biophysics, Rosalind Franklin University of Medicine and Science, 3333 Green Bay Road, Room 3.304, North Chicago, IL 60064

DOI:10.1523/JNEUROSCI.0312-14.2014

Copyright $\odot 2014$ the authors $\quad 0270-6474 / 14 / 3412304-09 \$ 15.00 / 0$
Experiments that use rodent models to investigate behavior changes evoked by chronic pain have somewhat inconsistent results. In one well described neuropathic model mice develop anxiety-like behavior after 4 weeks and depression-like behavior after 6-8 weeks (Yalcin et al., 2011). Other studies, which differ in pain model and experimental time course, find either no behavior changes (Urban et al., 2011), only increased anxiety-like behavior (Parent et al., 2012), only depression-like behavior (Hummel et al., 2008), or depression-like behavior along with cognitive deficits (Leite-Almeida et al., 2012).

The cellular changes underlying depression are unclear, but one contemporary hypothesis suggests that low levels of adult neurogenesis play a role (Samuels and Hen, 2011). Adult hippocampal neurogenesis is inhibited in some chronic pain models (Duric and McCarson, 2006; Terada et al., 2008; Mutso et al., 2012), suggesting that changes in neurogenesis may be involved in depression associated with chronic pain.

Because of variability between reports in the observation of pain-associated behavior changes, we initially evaluated the development of anxiety- and depressive-like behaviors in our hands following partial sciatic nerve ligation (PNL), a widely used model of neuropathic pain (Seltzer et al., 1990; Malmberg and Basbaum, 1998). We measured hippocampal adult neurogenesis in parallel to determine whether changes in new neurons track the behavioral effects, suggesting a possible link. We then asked 
whether changes in behavior and neurogenesis persist following resolution of allodynia. To accomplish this we used a sciatic nerve-cuffing procedure that produces effects on nociceptive sensitivity very similar to PNL (Mosconi and Kruger, 1996; Pitcher et al., 1999; Benbouzid et al., 2008) and removed the cuffs after $30 \mathrm{~d}$. We found that mechanical allodynia that developed following cuff placement completely disappeared when the cuff was removed. In contrast, changes in anxiety- and depressionlike behavior, memory function, and hippocampal neurogenesis persisted for at least 2 weeks after tactile sensitivity returned to its pre-injury level.

\section{Materials and Methods}

Animals. Procedures were approved by the NIMH Animal Care and Use Committee and in accordance with the Institute for Laboratory Animal Research Guide for the Care and Use of Laboratory Animals. Male C57BL/6J mice (bred on-site from The Jackson Laboratory stock), initially $80-120 \mathrm{~d}$ old, $28-32 \mathrm{~g}$, were singly housed following surgery. Nociceptive and behavioral testing was done in the morning, preceded by at least $1 \mathrm{~h}$ of acclimatization to the testing room.

Surgery. All surgery was performed under isoflurane anesthesia using aseptic technique. PNL was performed by tying 7-0 nonabsorbable monofilament polypropylene suture (Surgipro) around approximately one-half of the left sciatic nerve just past its exit between the obturator and piriformis muscles, as described previously (Malmberg and Basbaum, 1998). The procedure for production of neuropathic hypersensitivity by placement of a plastic tube around the sciatic nerve differed from a technique previously described in rats and in mice (Mosconi and Kruger, 1996; Pitcher et al., 1999; Benbouzid et al., 2008) by use of a tube that fit very loosely around the nerve. The left sciatic nerve was exposed as for PNL and exteriorized with forceps inserted under its main branch. A 4 $\mathrm{mm}$ long piece of $\mathrm{P} 90$ nontoxic, sterile polyethylene tubing (inner diameter $0.86 \mathrm{~mm}$ and outer diameter $1.27 \mathrm{~mm}$; Becton Dickinson Intramedic), already split lengthwise, was slid onto the exposed nerve. The forceps were removed and the nerve with the tube cuff was returned to its normal position. A similar surgical procedure was followed $30 \mathrm{~d}$ after the insertion of the cuff to remove it. The nerve and the cuff were exteriorized with forceps. An ophthalmic scissors was gently inserted between the nerve and the cuff, which were now covered with connective tissue. The cuff and the covering granulation tissue were cut with scissors and removed with forceps in three to four pieces. The nerve was inspected for any remaining plastic, which was removed, and then repositioned between the femoral muscles. The sciatic nerve was similarly exposed for sham surgery. Following each surgery the skin was closed with wound clips and analgesia (ketoprofen $5 \mathrm{mg} / \mathrm{kg}$, i.p.) and fluids were provided for $3 \mathrm{~d}$.

Nociceptive testing. Tactile sensitivity was measured using von Frey filaments (North Coast Medical), and the 50\% threshold was calculated by Dixon's up and down method as described previously (Chaplan et al., 1994).

Behavior testing. All behavior tests were conducted in the morning in a dedicated behavior testing room under bright illumination during the light phase and video recorded. Video records were analyzed with "Top Scan" software (Clever Systems). The test equipment included a standard plastic box for open-field and novel-object recognition tests and O-maze and Y-maze apparatus from Phenome Technologies. Tests were conducted as we described previously (Coutellier and Usdin, 2011; Coutellier et al., 2011). Time spent in the central $50 \%$ of the open field, time spent in the O-maze open arms, and the number of Y-maze spontaneous alternations are presented as a percentage of the total time ( $5 \mathrm{~min}$ in each case) or total number of entries. These were each single-trial tests. The acquisition and test phases of the novel-object recognition test were each 5 min long, with a 5 min interval between the phases. The objects differed in color, texture, and form, were smaller than the mouse, and odor neutral. The three objects were randomly selected for each animal. The time when the mouse's nose was $<2 \mathrm{~cm}$ from the object was defined as object exploration. The preference index (PI) for each animal was calculated from the time spent exploring the novel object $(N)$ and the familiar object $(F)$ during the test phase: $\mathrm{PI}=100 \times(N-F) /(N+F)$.

The last $4 \mathrm{~min}$ of a $6 \mathrm{~min}$ forced-swim test, performed in $20 \mathrm{~cm}$ diameter transparent acrylic cylinders filled with tap water $(15 \mathrm{~cm}$ depth, $21-23^{\circ} \mathrm{C}$ ), were manually scored by two observers blind to animal status. The mouse was considered to be immobile if it was not actively propelling itself in the water, climbing the walls, or making active movements other than breathing.

Separate groups of mice were evaluated in the open-field or elevated $\mathrm{O}$-maze test and then $5 \mathrm{~d}$ later in the forced-swim test, or in the Y-maze test followed after another $5 \mathrm{~d}$ by the novel-object recognition test.

Immunohistochemistry. Mice that were used for evaluation of neurogenesis were distinct from those used for behavioral experiments. They were left undisturbed in their home cages for $50 \mathrm{~d}$ after the initial nerve cuff implantation, $20 \mathrm{~d}$ after nerve cuff removal, or $35 \mathrm{~d}$ after PNL surgery, and then all mice in an experiment were perfused at the same time with $4 \%$ paraformaldehyde under deep anesthesia. Eight sets of $30 \mu \mathrm{m}$ sections were cut on a vibrating microtome. Each set consisted of six evenly spaced sections that included a hippocampal area spanning from -1.3 to $-2.7 \mathrm{~mm}$ relative to bregma. Incubations with primary antibodies were performed at $4^{\circ} \mathrm{C}$ in $0.1 \mathrm{M}$ PBS with $3 \%$ donkey serum. Antigen retrieval, performed by incubating sections for $15 \mathrm{~min}$ at $90^{\circ} \mathrm{C}$ in $0.01 \mathrm{M}$ citric acid (Tóth and Mezey, 2007), was done before labeling with a mouse antibody to proliferating cell nuclear antigen (anti-PCNA; catalog sc-56; Santa Cruz Biotechnology), which was diluted 1:10K and incubated for $48 \mathrm{~h}$. Incubations with a goat antibody to doublecortin (antiDCX; catalog sc-8066; Santa Cruz Biotechnology), 1:1K dilution, $72 \mathrm{~h}$ incubation, and rabbit anti-FosB (mAb 5G4; Santa Cruz Biotechnology), $1: 2 \mathrm{~K}$ dilution for $3 \mathrm{~h}$, were performed without antigen retrieval. Incubation with appropriate biotinylated secondary antibodies (Jackson ImmunoResearch), 1:2K dilution, $3 \mathrm{~h}$ at room temperature, followed the primary antibody incubations. Visualization was done with DAB-Ni (PCNA, FosB) or DyLight 488-tyramide (DCX; Hunyady et al., 1996) following incubation with $\mathrm{ABC}$ elite reagents (Vector Laboratories) used as described by the supplier. Immunofluorescent sections were incubated in DAPI solution to label nuclei. Immunopositive cells in the dentate gyrus were counted on one side of the six sections per animal based on bilaterally equal effects on hippocampal neurogenesis of one-sided peripheral injury in a previous study (Mutso et al., 2012) and as observed in the PNL experiment described here. The granule cell layer, amygdalar nuclei, and dorsal horn of the spinal cord were outlined in ImageJ using DAPI staining or background as reference. The resulting area was multiplied by the section thickness and expressed in cubic millimeters. The cell density was calculated by dividing the number of cells counted by the volume of the counted area and averaged per animal. All counting was performed blind to the treatment condition.

Microscopy. Bright-field microscopy was used for visualization of PCNA-IR and FosB-IR. Images were obtained on a Zeiss Axioplan 2 microscope equipped with an AxioCam HR camera and AxioVision software (Zeiss). All PCNA-IR-positive cells within the subgranular zone, defined as a distance within two cell body diameters of the inner edge of the granule cell layer, were counted on both blades of the dentate gyrus. FosB-IR cells were counted in outlined areas of matching sections. Confocal microscopy was used for visualization of DCX-IR-positive cells. Fluorescent labeling was detected in representative sections using a Zeiss LSM510 confocal microscope in the NINDS Intramural Light Imaging Facility. The tissue background and the DAPI staining permitted visualization of landmarks and cell nuclei. Single optical sections that included the entire dentate gyrus on one side were acquired with a $10 \times$ objective ( $0.7 \times$ optical zoom) using 405 and $488 \mathrm{~nm}$ lasers at 2048 by 2048 pixel resolution. The photographs were viewed at high magnification and individual cells were manually identified and marked with ImageJ software for counting (ImageJ, NIH image, Research Service Branch, Bethesda, MD). Only cells with DCX-IR and a DAPI-labeled nucleus were counted.

Radioimmunoassay. Serum corticosterone levels were measured using the ImmuChem Double Antibody ${ }^{125}$ I RIA kit manufactured by MP Biomedicals. All samples were processed together and the sensitivity of the assay was $7.7 \mathrm{ng} / \mathrm{ml}$ of serum. 
Statistical analysis. Data are presented as mean \pm SEM with 6-16 animals per group. Student's $t$ test was used for two group comparisons and the preference index for each group in the novel-object recognition test. One-way ANOVA with repeated measures was used for three group comparisons and two-way ANOVA for surgery and time interaction. Post hoc analysis of one-way ANOVA data was done with Dunnett's or Newman-Keuls post-test and the Bonferroni post-test was used for twoway ANOVAs, as indicated in the text or figure legend. The accepted level of significance was $p<0.05$ in all tests.

\section{Results}

Comparison between sensory, behavioral, and hippocampal changes after PNL and sciatic nerve cuffing Tactile hypersensitivity developed rapidly following PNL and persisted for at least $35 \mathrm{~d}$, the endpoint for these experiments. The average mechanical withdrawal thresholds of the mouse groups were not different before the surgery. The average threshold decreased to $0.3 \pm 0.12 \mathrm{~g}$ within $5 \mathrm{~d}$ after the surgery in the group with PNL, which differed significantly from the simultaneously measured control group threshold of $5.5 \pm 1.5 \mathrm{~g}$ (Fig. $1 A$; two-way repeated-measures ANOVA, surgery vs time, $F_{(3,64)}=3.8, p<0.001$ for interaction; $n=8$ per group). We began behavior testing $35 \mathrm{~d}$ after the nerve ligation. In the open-field test the PNL group spent less time in the center (Fig. $1 B$; $t$ test, $t_{(10)}=4.8, p<$ $0.001, n=6$ per group), an indication of increased anxiety-like behavior. The groups did not differ in the total distance traveled (Control $144.9 \pm 9.2 \mathrm{~cm}$ vs PNL $151.8 \pm 20.1 \mathrm{~cm}$ ). We also compared these groups using the forced-swim test, in which active swimming during the test is considered a coping or survival mechanism and immobility during the test is used as a measure of helplessness or depression-like behavior. Immobility time increased following PNL (Fig. $1 C$; $t$ test, $t_{(10)}=4.8, p<0.001, n=$ 6 per group), consistent with increased susceptibility to depression-like behavior.

Placement of a plastic tube around the sciatic nerve led to behavioral changes very similar to the sensory and behavior changes that were observed after PNL. The average tactile threshold of the mice in the group with nerve cuffs decreased from $4.2 \pm$ $0.74 \mathrm{~g}$ before surgery to $0.5 \pm 0.14 \mathrm{~g} 5 \mathrm{~d}$ after surgery (Fig. $1 D$; two-way repeated-measures ANOVA, surgery vs time, $F_{(3,42)}=$ 5.7, $p<0.01$ for interaction, $n=8$ per group). The cuffed mice also spent less time in the open arms of an elevated O-maze (Fig. $1 E$; $t$ test, $t_{(17)}=2.3, p<0.05, n=9$ for the control and 10 for the cuffed group). As in the previous experiment the groups did not differ in the total distance traveled (Control $80.7 \pm 10.3 \mathrm{~cm}$ vs Cuff $82.2 \mathrm{~cm} \pm 8.9$ ). The immobility time of the cuffed group in the forced-swim test was increased when compared with the control group (Fig. $1 F$; $t$ test, $t_{(16)}=3.8, p<0.01, n=8$ for the control and 10 for the cuffed group).

The subgranular zone of the dentate gyrus contains cells that continue to divide and generate neurons throughout adulthood. Their proliferation and differentiation rates are significantly affected by environmental factors (Glasper et al., 2012). We inves-
B
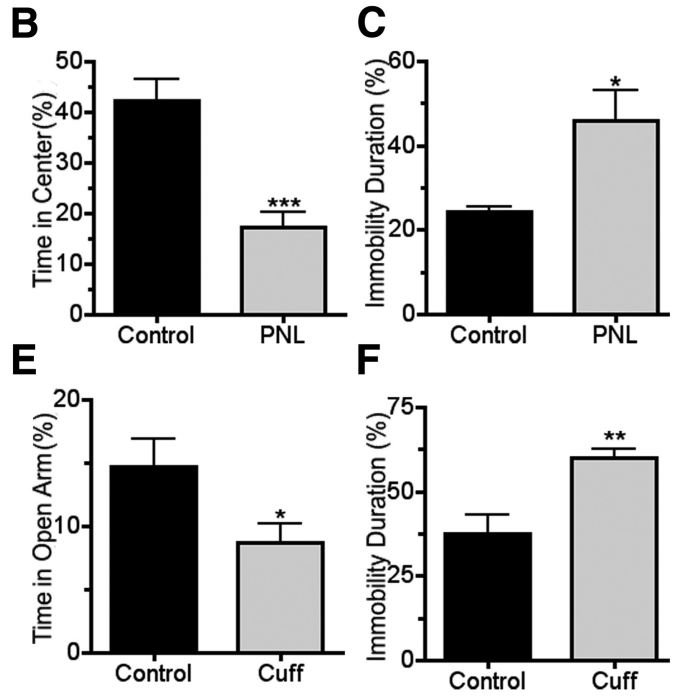

Figure 1. Comparison of the effects of PNL and sciatic nerve cuffing. Mechanical thresholds decreased within $5 \mathrm{~d}$ following PNL percentage of time during the last 4 (of 6) test minutes. Time courses were evaluated using two-way repeated-measures ANOVA ${ }^{*} p<0.001 . N=8$ per group for data in $\boldsymbol{A}$ and $\boldsymbol{D} ; 9$ for the control and 10 for the cuffed group in $\boldsymbol{E} ; 8$ and 10 , respectively, for the

tigated the status of hippocampal neurogenesis $35 \mathrm{~d}$ after either PNL or nerve cuff placement by evaluating the expression of PCNA and DCX (Fig. 2). Following PNL, the number PCN+ cells was reduced by 70\% ( $t$ test, $t_{(20)}=7.06, p<0.001, n=11$ for each group) and the number of DCX + cells was reduced by $60 \%$ ( $t$ test, $t_{(22)}=4.89, p<0.001, n=12$ for each group). Following sciatic nerve cuffing, the number $\mathrm{PCN}+$ cells was reduced by $60 \%\left(t\right.$ test, $t_{(10)}=8.25, p<0.001, n=6$ for each $)$ and the number of DCX + cells was reduced by $33 \%\left(t\right.$ test, $t_{(10)}=3.59$, $p<0.01, n=6$ for each). Thus, the number of immunolabeled cells was significantly reduced following either of the sciatic nerve perturbations, and for both of the markers, indicating suppression of adult neurogenesis by both sciatic nerve perturbations.

\section{Sensory, behavior, and cognitive changes in mice in a reversible peripheral neuropathy model}

Having established that we observe anxiety- and depression-like behaviors and impairment of neurogenesis in a neuropathic pain model we wanted to know if this phenotype changes with recovery from injury. Sterile cuffs were placed around the left sciatic nerve and removed from half of the animals $30 \mathrm{~d}$ later. Mechanical sensitivity was evaluated in animals with nerve cuffs (ipsilateral and contralateral to the surgery), after cuff removal in a separate group (ipsilateral side), and in a sham surgery group (ipsilateral side; sham surgeries were performed at the time of the cuff-removal surgery). There was little variation over time in the mechanical withdrawal thresholds of the ipsilateral hindpaws of mice with sham surgery or the contralateral paws of animals with cuff placement. The mechanical sensitivity of the mice with nerve cuffs rapidly increased and stayed high while cuffs were in place, but rapidly decreased to control levels when cuffs were removed (Fig. 3A). One-way repeated-measures ANOVA with 
A
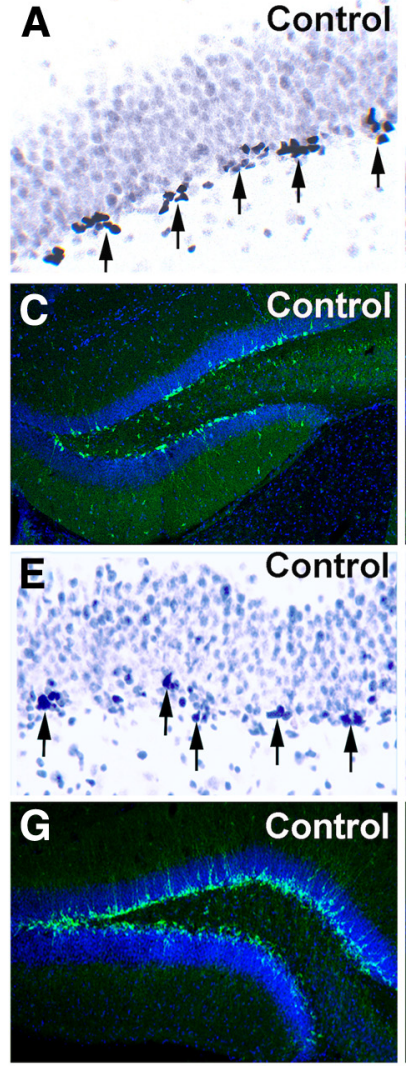
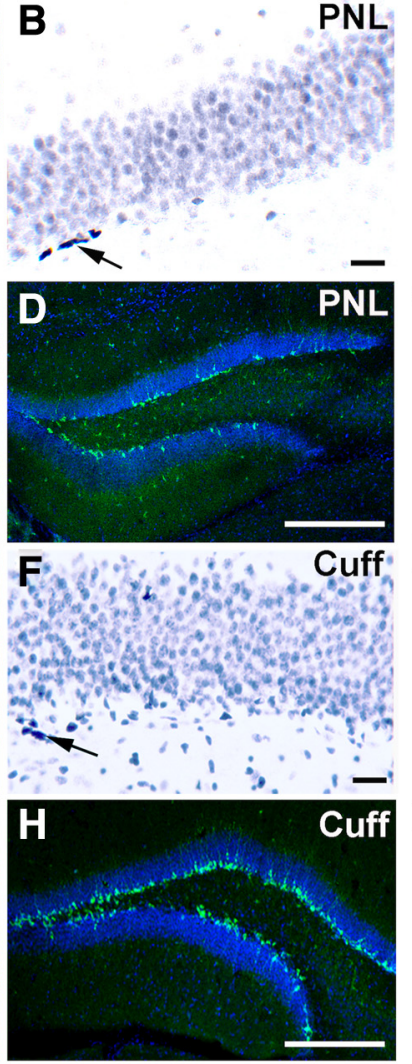
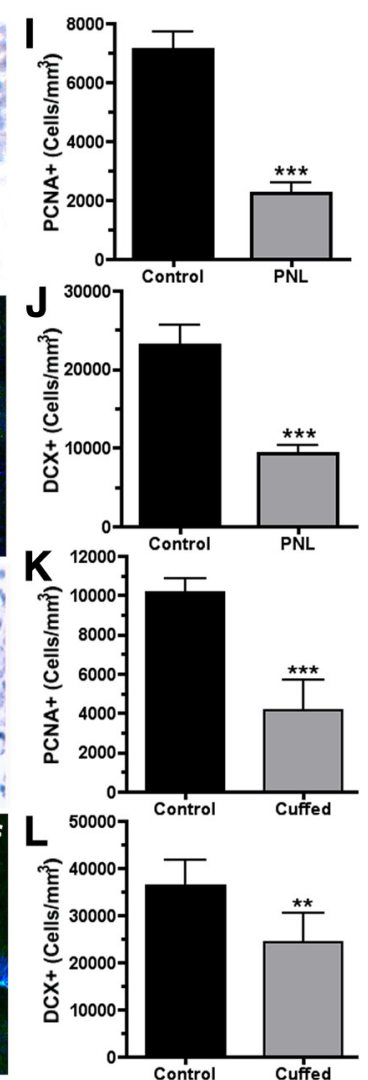

Figure 2. Neurogenesis in the hippocampal dentate gyrus following $35 \mathrm{~d}$ of PNL or $35 \mathrm{~d}$ of sciatic nerve cuffing. The effects of PNL and sciatic nerve cuffs on hippocampal neurogenesis were evaluated by counting dividing cells identified with PCNA-IR (images in $\boldsymbol{A}, \boldsymbol{B}, \boldsymbol{E}$, and $\boldsymbol{F}$ arrows; cell counts in $\boldsymbol{I}$ and $\boldsymbol{K}$ ) and immature neurons identified by DCX-IR (images in $\boldsymbol{C}, \boldsymbol{D}, \boldsymbol{G}, \boldsymbol{H}$, green cells; cell counts in $\boldsymbol{J}$ and $\boldsymbol{L}$ ). The data presented are from the dorsal hippocampus. Results were qualitatively similar in the ventral hippocampus. Scale bars: $\boldsymbol{B}, \boldsymbol{F}, 20 \mu \mathrm{m} ; \boldsymbol{D}, \boldsymbol{H}, 200 \mu \mathrm{m}$. $t$ test, ${ }^{* *} p<0.01$ and ${ }^{* * *} p<0.001 . N=11$ per group for the data in $\boldsymbol{I}, n=$ 12 per group for the data in $J$, and $n=6$ per group for the data in $\boldsymbol{K}$ and $\boldsymbol{L}$.

Newman-Keuls post-test $\left(F_{(4,92)}=20.06, p<0.001, n=8\right.$ per group) using surgical group as the independent measure showed significant differences between the mechanical thresholds of all experimental groups except between the "Sham" group and the "Contralateral Paw" group. Two-way repeated-measures ANOVA with surgery and time as factors (surgery vs time, $F_{(24,224)}=2.7, p<0.001$ for interaction, $n=8$ per group) followed by Bonferroni post-test indicated that the mechanical withdrawal threshold was significantly decreased on the ipsilateral side $(0.39 \pm 0.14 \mathrm{~g}$ average over the $50 \mathrm{~d}$ experiment $)$ of mice cuffed for the full duration of the experiment when compared with the sham group $(3.7 \pm 0.74 \mathrm{~g}$ average over the $50 \mathrm{~d}$ experiment $)$. However, the mechanical withdrawal threshold of the paw ipsilateral to the cuff was no longer significantly different from contralateral paws or sham paws $5 \mathrm{~d}$ after the cuff removal. The signs of mechanical allodynia had completely disappeared from the cuff-removed group $10 \mathrm{~d}$ after cuff extraction. Their mechanical thresholds were significantly different from that of mice with tubing still in place. Cuff placement onto the left sciatic nerve appeared to cause a slight decrease of the contralateral paw thresholds 5 and $10 \mathrm{~d}$ after the cuff placement and the thresholds of the sham surgery group also appeared to briefly decrease after surgery, but these effects did not reach statistical significance.

Having established that signs of mechanical allodynia are reversed following extraction of the sciatic nerve cuffs, we compared the behavior of mice with cuffs in place and ongoing nociceptive hypersensitivity, mice with cuffs removed and noci- ceptive recovery, and sham surgery controls. We first evaluated anxiety-like behavior using the elevated O-maze $15 \mathrm{~d}$ after the tubing was removed, which was $45 \mathrm{~d}$ after it was implanted. Animals in both experimental groups, with cuffs present and with cuffs removed, spent much less time in the open arms than the controls (Fig. 3B; one-way ANOVA, $F_{(2,22)}=5.4, p<0.05 n=8$ per group). The total distance traveled did not significantly differ between groups (Sham 89 $\mathrm{cm} \pm 10.4$, Cuffed $96 \mathrm{~cm} \pm 9.4$, and CuffRemoved group $85.4 \pm 8.3 \mathrm{~cm}, p>0.05$ ). The immobility time also differed between the groups when they were evaluated in the forced-swim test. The cuffed and cuff-removed groups had significantly greater immobility time than the sham animals (Fig. 3C; one-way ANOVA, $F_{(2,21)}=5.5 p<0.05, n=8$ per group).

We next evaluated spontaneous alternation behavior during free exploration of a Y-maze, which is dependent upon short-term or working memory. Arm entry alternation was significantly less for the cuffed and cuff-removed than the control mice (Fig. 3D; one-way ANOVA, $F_{(2,23)}=6.7, p<0.01, n=8$ per group) . Number of arm entries, speed, and distance traveled were not different between the three groups (data not shown). We also performed a novel-object recognition test with these mice. This test is based on the natural propensity of rodents to spend more time exploring an unfamiliar or novel object than a familiar one, and depends upon short-term memory. While the total object exploration time did not differ between the groups, investigation of the novel object was significantly greater than chance for the control group but not for either the cuffed or cuff-removed groups [Fig. 3E; one-sample $t$ tests, control $t_{(15)}=3.1 p<0.01(n=16)$, cuffed $t_{(15)}=0.28 p>$ $0.5(n=15)$, cuffs removed $\left.t_{(6)}=0.67 p>0.5(n=7)\right]$.

The presence of anxiety- and depression-like behavior and suppressed neurogenesis was not associated with a detectible change in the baseline HPA activity in mice with nerve cuff placement, as measured by the corticosterone levels in blood samples obtained immediately after the circadian nadir [Control 71.6 \pm $26.3 \mathrm{ng} / \mathrm{ml}(n=6)$, Cuffs present $61.3 \pm 18.2 \mathrm{ng} / \mathrm{ml}(n=6)$, Cuffs removed $64.1 \pm 18.9 \mathrm{ng} / \mathrm{ml}(n=7)]$.

\section{Assessment of hippocampal neurogenesis in mice with sciatic} nerve cuffs present or removed

Adult neurogenesis progresses through well defined stages of proliferation, fate specification, differentiation, and synaptic integration. PCNA is expressed by cells that are in a state of proliferation and DCX is expressed during neuronal differentiation. Clusters of PCNA + dividing cells were present in the subgranular zone of the dentate gyrus of all three groups. Mice with nerve cuffs present and mice with nerve cuffs removed had significantly fewer PCN+ cells than the control group (Fig. 4A-C). The number of cells with DCX-IR (Fig. $4 D-I$ ), reflecting the population of 0 - to 4 -week-old neurons, was also reduced in both the cuffed 
group and the cuff-removed group evaluated $20 \mathrm{~d}$ after the time of nerve cuff extraction (PCN+: one-way ANOVA, $F_{(2,15)}=17 p<0.001, n=6$ for each group; DCX+: one-way ANOVA, $F_{(2,18)}=24 p<$ $0.0001, n=6$ for each group). The maturation state of DCX + cells can be further classified based on their morphology. Neurons with apical dendrites that penetrate the granule cell layer are considered to be postmitotic (Plümpe et al., 2006). In contrast to the decrease in the total number of DCX-IR neurons, the proportion of the DCX-IR neurons present that had a vertical dendrite crossing the granule cell layer did not differ among the groups (Fig. $4 G-I)$.

\section{Evaluation of FosB expression}

FosB is a product of the immediate early gene fosB with a relatively long half-life ( $6 \mathrm{~h}$ in some reports), and its expression is elevated in some persistent pain models (Nestler et al., 1999, Luis-Delgado et al., 2006). We counted the number of neurons with labeling by an antibody to FosB (FosB-IR) on brain sections from control/ sham, cuffed, and cuff-removed mice. All three groups had robust expression of FosB-IR in many brain regions (Fig. 5). We compared expression in the central amygdaloid nucleus (CE), basolateral amygdaloid nucleus (BLA), and the dorsal horn of the spinal cord (DH) between the experimental groups. The number of cells with FosB-IR was increased in the $\mathrm{DH}$ of animals with nerve cuffs in place, but not in those from which cuffs were removed 3 weeks earlier (Fig. 5L; one-way ANOVA, $F_{(2,14)}=33, p<0.001, n=6,5$, and 6 for the sham, cuffed, and cuff-removed conditions, respectively). In the CE (Fig. $5 K$; one-way ANOVA, $F_{(2,12)}=16, p<0.001$, $n=6,4$, and 6 for the sham, cuffed, and cuff-removed conditions, respectively), as in the DH, the number of FosB-IR neurons was elevated in animals with cuffs in place and not in animals examined 3 weeks after cuff removal. In the BLA, in contrast, FosB-IR was elevated in animals with cuffs in place, and also in mice from which the nerve cuffs were removed 3 weeks earlier (one-way ANOVA, $F_{(2,12)}=$ 6.7, $p<0.05, n=6,5$, and 6 for the sham, cuffed, and cuffremoved conditions, respectively).

\section{Discussion}

Mice with PNL or sciatic nerve cuffs in place for $30 \mathrm{~d}$ developed mechanical allodynia, anxiety- and depression-like behavior, memory impairment, and suppressed hippocampal neurogenesis. We found that when the nerve cuffs were removed these behavior changes and decreased hippocampal neurogenesis remained present following complete resolution of the tactile hypersensitivity. While

B cuff-removed group.
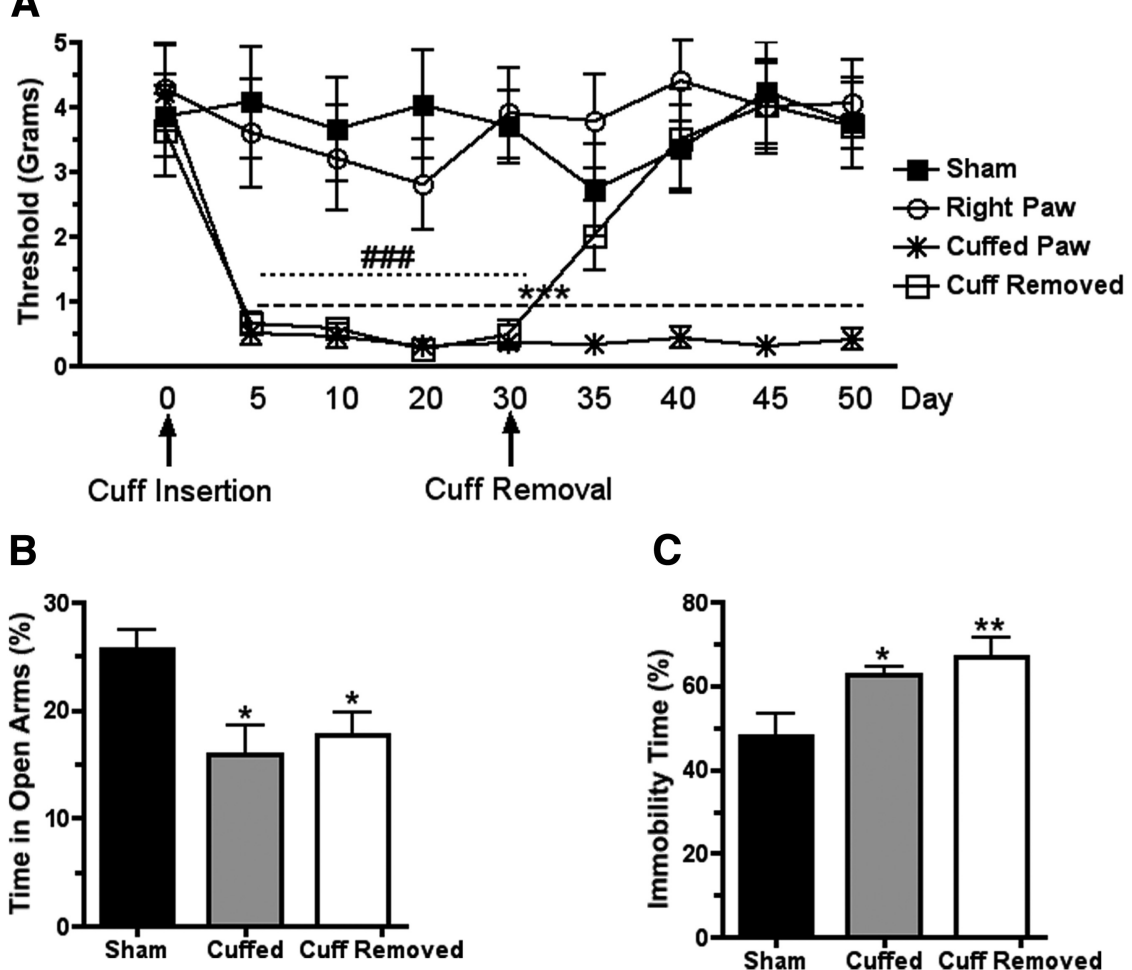

C

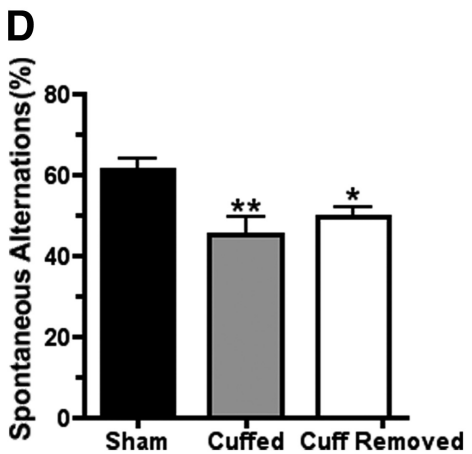

E
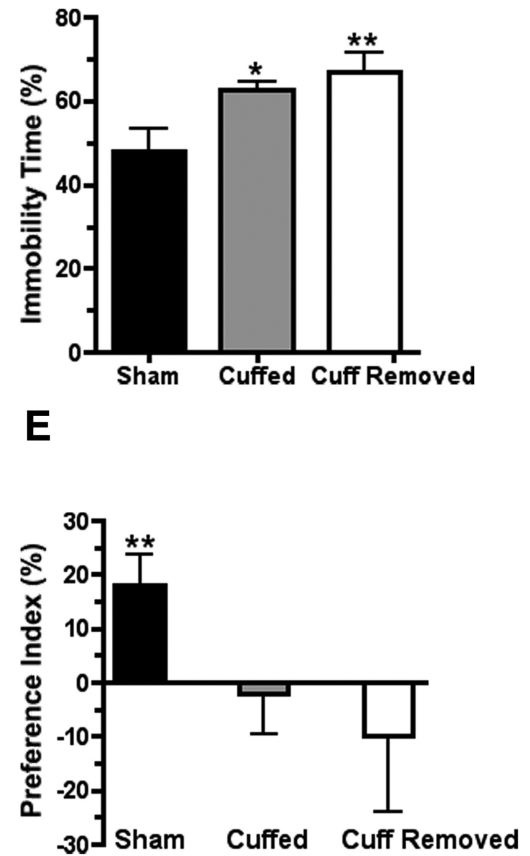

Figure 3. Evaluation of tactile allodynia and behavior after sciatic nerve cuffing and subsequent cuff removal. Experimenta groups are as follows: (1) the left hindpaw of a group that received left-sided sham surgery at the $30 \mathrm{~d}$ time point (Sham), (2) the left paw of a group with a nerve cuff placed on the left sciatic nerve at time 0 (Cuffed Paw or Cuffed), (3) the right hindpaw of the cuffed animals (Right Paw), and (4) the left hindpaw of mice with a nerve cuff placed on the left sciatic nerve on day 0 and removed on day 30 (Cuff Removed). $\boldsymbol{A}$, Shows the tactile sensitivity thresholds evaluated using von Frey filaments. $\boldsymbol{B}$, Shows anxiety-like behavior measured as time spent in the open arms of an elevated 0 -maze, $15 \mathrm{~d}$ after cuff removal. $\boldsymbol{C}$, Shows depression-like behavior as measured by the immobility duration in a forced-swim test, $20 \mathrm{~d}$ after cuff removal. $\boldsymbol{D}$, Shows spontaneous alternations in the Y-maze test conducted with a different cohort of mice $15 \mathrm{~d}$ after cuff removal. $\boldsymbol{E}$, Shows the results of a novel-object recognition test conducted $5 \mathrm{~d}$ after the $Y$-maze test. Periods of significant difference $(p<0.001)$ from control values in the time course analyzed with repeated-measures two-way ANOVA and Bonferroni post-test are indicated by \#\#\# and *** Behavioral data were analyzed using one-way ANOVA and Dunnett's post-test; ${ }^{*} p<0.05$ and ${ }^{* *} p<0.01 . \mathrm{N}=8$ per group for each data animal group, except for $\boldsymbol{E}$, which was analyzed with one-sample $t$ tests and $n=16$ for the control and cuffed groups and 7 for the

mechanical allodynia subsided within $10 \mathrm{~d}$ of tube extraction, behavior changes and suppression of neurogenesis persisted to the latest time point examined in this study (2-3 weeks after normalization of mechanical sensitivity). These observations suggest that persistent effects of a painful injury on mood, behavior, and neurogenesis may not require ongoing nociceptive signaling.

Central sensitization that develops following injury is thought to contribute to chronic pain and the deleterious effects of pain on mood and cognitive function in animal models (Narita et al., 


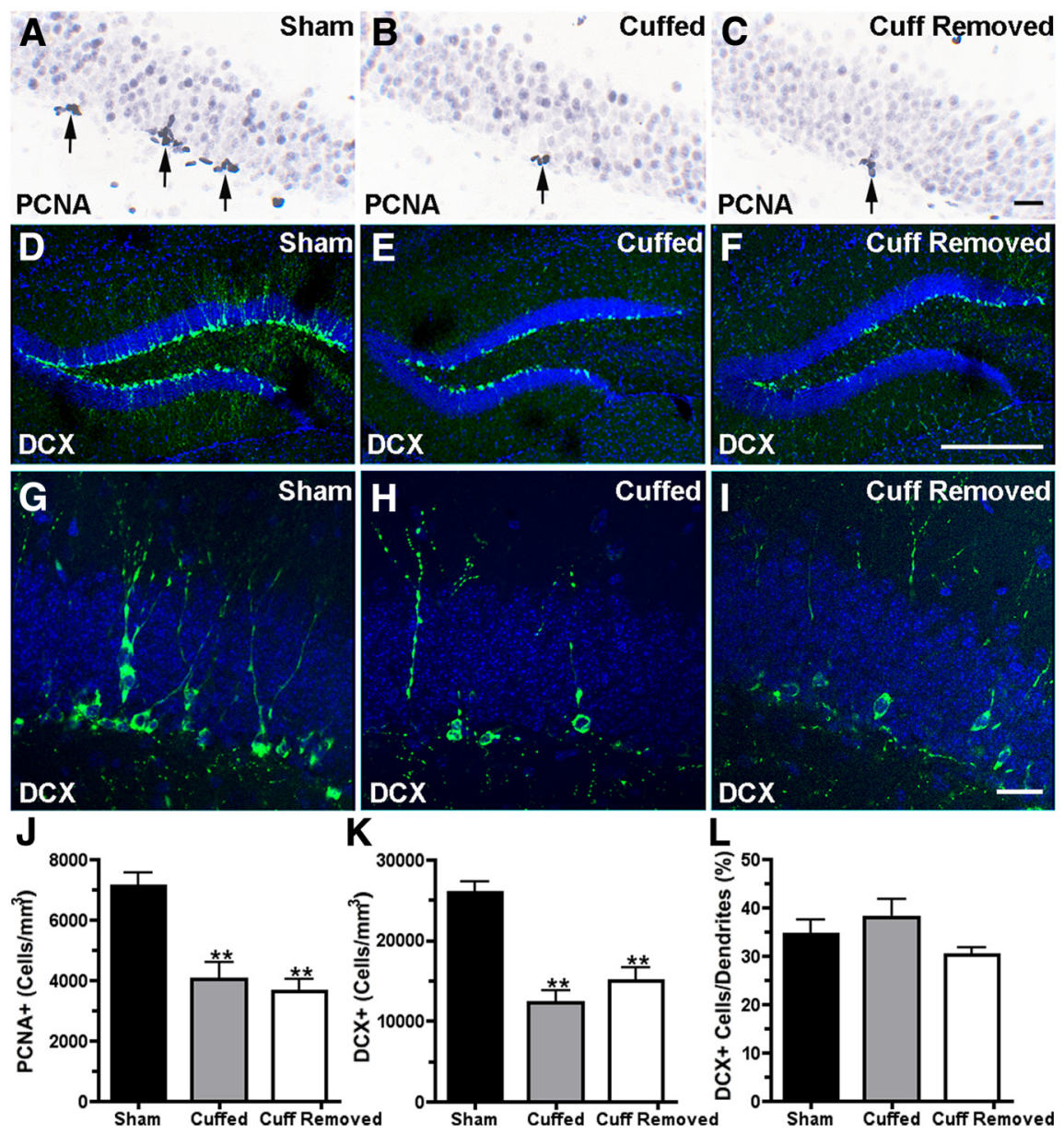

Figure 4. $A-C$, Show PCNA-IR (arrows). Changes in PCNA-IR cell density are shown in J. D-I, Show DCX-IR (green labeling). Changes in DCX-IR cell density are seen in $\boldsymbol{K}$. The bar graph in $\boldsymbol{L}$ shows the percentage of the DCX-IR neurons with dendrites that extended through the granule cell layer. Mice used for immunohistochemistry were not used for any behavior tests and were killed at the same time, $50 \mathrm{~d}$ after cuff insertion (which is $20 \mathrm{~d}$ after the cuff removal). Scale bars: $\boldsymbol{A}-\boldsymbol{C}, 20 \mu \mathrm{m} ; \boldsymbol{D}-\boldsymbol{F}, 200 \mu \mathrm{m}$. Data analyzed using one-way ANOVA and Dunnett's post-test; ${ }^{* *} p<0.01$ and ${ }^{* * *} p<0.001 . N=6$ per group for each group.

creased in the BLA of cuffed and cuff-removed/recovered animals, which parallels the persistent anxiety- and depressionrelated behavior and impaired neurogenesis in these animals, and is consistent with BLA modulation of anxiety, depression, hippocampal neurogenesis, and cognition (Rainnie et al., 2004; Ji et al., 2010; Kirby et al., 2012; Felix-Ortiz et al., 2013). In contrast, FosB-IR expression was increased in the $\mathrm{CE}$ of mice with ongoing pain but not in the CE of the cuff-removed/recovered group. It appears that cessation of nociceptive input to the $\mathrm{CE}$ leads to a rapid decline in FosB expression and, presumably, normalization of its neuronal activity, which is consistent with a greater effect of spinal sensory information in the CE than BLA. A recent study showed that cytotoxic lesion of the BLA before sciatic nerve constriction injury prevents the development of chronic neuropathic pain, as measured by thermal hypersensitivity and tactile allodynia (Li et al., 2013). This observation, in combination with ours, suggests that even though the BLA provides a major input to the $\mathrm{CE}$ that may be necessary for development of allodynia, activation of the BLA is not sufficient to maintain nociceptive hypersensitivity in the absence of another source of $\mathrm{CE}$ activation.

The sciatic nerve cuff procedure used in this study recapitulates several of the nociceptive and/or behavioral effects that emerge after peripheral nerve injury in other studies (Malmberg and Basbaum, 1998; Pitcher et al., 1999; Benbouzid et al., 2008; Yalcin et al.,

2006; Kodama et al., 2011; Alba-Delgado et al., 2013; CardosoCruz et al., 2013) and in humans (McWilliams et al., 2003; Ling et al., 2007; Kim et al., 2012). Whether mood and cognitive changes during chronic pain are a direct consequence of ongoing pain perception or become independent of it has significant consequences for research and treatment. Data in this study, supporting their dissociation, suggest that the neurobiological link between somatic injury and affective and cognitive functions is an important research area, and that mood disorders may not necessarily resolve when pain or its initial cause is appropriately treated.

The amygdala plays an important role in pain processing. The CE receives nociceptive input from the spinal cord via the parabrachial nucleus (Bernard et al., 1989; Sarhan et al., 2013), and its descending projections contribute to the modulation of pain (Pedersen et al., 2007). The BLA receives more processed pain information and projects to the CE as well as to cortical areas involved in affective dimensions of pain. Changes in amygdalar function during persistent or neuropathic pain include increased corticotropin-releasing hormone production, excitability, and CE firing rate (Fu and Neugebauer, 2008; Ren and Neugebauer, 2010; Rouwette et al., 2012). Our results also point to changes in neuronal activity within the amygdala, based on an increased number of FosB-IR cells. FosB-IR expression was similarly in-
2011; Vacca et al., 2013) and adds the ability to reverse the lesion. Use of relatively loose tubing (P90 vs P20 in other mouse experiments; Benbouzid et al., 2008) may have prevented irreversible nerve damage and facilitated tube extraction without nerve injury. Incomplete recovery that was reported in a study in which $\mathrm{P} 90$ tubing placed around rat sciatic nerve was removed after only $4 \mathrm{~d}$ (Dableh et al., 2011) may be attributed to that cuff being significantly tighter on a rat nerve or to performing the extraction in an acute postsurgical phase. A major advantage of the cuff removal approach described here is that it provides the opportunity to reverse the lesion at a predetermined time point and to achieve a uniform pattern of recovery from neuropathic mechanical hypersensitivity. This may be either a true reversal, reflecting loss of the irritation from the cuff, or a compensatory suppression of hypersensitivity. The presence of an increased number of FosB-IR neurons in the spinal cord DH when nerve cuffs are in place, and the similarity to the number of labeled cells in control animals after cuff removal, indicates that removing the nerve cuff leads to a significant decrease in sensory signaling and argues against residual pain from possible permanent effects on the sciatic nerve from the cuff or surgery. Evaluation of the nociceptive phenotype in these experiments was limited to mechanical allodynia. Previous reports of sciatic nerve cuff- 
ing in mice indicate that thermal hypersensitivity, which develops after nerve injury, has largely resolved at the time points we investigated (Benbouzid et al., 2008). Evaluation of additional nociceptive parameters, and particularly those that more closely reflect human experience, will be important to understand the clinical relevance and experimental utility of this model with respect to chronic pain. Additional measures of behavior will be important to understand its relevance to mood disorders. Determining how long the changes in behavior and neurogenesis persist following the resolution of sensory changes, and identifying other changes in behavior, cellular function, or gene expression will be important steps in characterizing the underlying mechanisms. In any case, this paradigm will facilitate experiments that distinguish between long-term consequences of persistent pain on brain function or morphology, and effects that are associated with ongoing sensory activity.

Some of the effects of nerve cuffing may result from the chronic stress or anxiety that it produces. The effects of stress on neurogenesis vary widely between studies, but the inhibition of neurogenesis observed in this study following PNL $(\sim 70 \%)$ and nerve cuffing $(\sim 48 \%)$ is equal to or greater than that observed in most studies that use chronic psychological or physical stress procedures $(\sim 25-$ 30\%; Czéh et al., 2001; Pham et al., 2003; Hanson et al., 2011; Schoenfeld and Gould, 2012). The relatively few studies of recovery from chronic stress vary significantly in the stressor, outcome measures, and the extent of recovery reported. We used a $20 \mathrm{~d}$ recovery period following cuff removal based on several rodent studies that show significant recovery from chronic stress-induced changes in behavior and corticosterone levels (Zhao et al., 2012), gene expression, or neurogenesis parameters near this time (Conrad et al., 1999; Heine et al., 2004). We did not observe a significant return toward control levels in the behavioral or neurogenesis parameters measured. It may be that the neuropathic lesion, which is present $24 \mathrm{~h}$ per day, is simply a stronger stressor than that in studies with smaller effects or ones that last less time. It may also be the case that the effects of nerve cuffing are not mediated by well characterized stress mechanisms (i.e., peripheral glucocorticoid secretion). The absence of a difference in the plasma concentration between the experimental groups, which is consistent with previous reports (Yalcin et al., 2011; Benedetti et al., 2012; Rouwette et al., 2012), supports the later notion. In combination with its relative simplicity, this may make the cuff procedure a particularly useful chronic stress paradigm. Comparison of other parameters, such as the diurnal cycle of corticosterone secretion, responsiveness of the HPA axis, gene expression changes, and additional behaviors will show whether there are significant qualitative differences from other stress par- adigms. The continued FosB elevation in the BLA when mechanical sensitivity returns to baseline, but behavior and neurogenesis changes persist, provides a starting point for identifying the "trace" that remains.

The paradigm described in this study may prove useful for investigating the mechanisms that contribute to mood disorders associated with chronic pain. By examining the effects on mood-related behaviors of discrete lesions or perturbations, such as those that can be created with optogenetic or pharmacogenetic reagents, before or after removing a nerve cuff, it should now be possible to identify the contributions of specific brain regions or circuits to the development or maintenance of the behavior changes. Some of these circuits are likely to also contribute to mood changes in other conditions. In conclusion, we observed a striking difference between rapid resolution of mechanical hypersensitivity achieved by removing its initial cause and persistence of an associated behavioral phenotype. We also described a paradigm that, by reversing the initiating factor, provides a means to investigate the long-term consequences of persistent nociception on rodent behavior and the underlying brain plasticity, and to distinguish lasting consequences from direct effects of nociceptive signals. These 
observations will facilitate research on the mechanisms underlying mood disorders.

\section{References}

Alba-Delgado C, Llorca-Torralba M, Horrillo I, Ortega JE, Mico JA, SánchezBlazquez P, Meana JJ, Berrocoso E (2013) Chronic pain leads to concomitant noradrenergic impairment and mood disorders. Biol Psychiatry 73:54-62. CrossRef Medline

Benbouzid M, Pallage V, Rajalu M, Waltisperger E, Doridot S, Poisbeau P, Freund-Mercier MJ, Barrot M (2008) Sciatic nerve cuffing in mice: a model of sustained neuropathic pain. Eur J Pain 12:591-599. CrossRef Medline

Benedetti M, Merino R, Kusuda R, Ravanelli MI, Cadetti F, dos Santos P, Zanon S, Lucas G (2012) Plasma corticosterone levels in mouse models of pain. Eur J Pain 16:803-815. CrossRef Medline

Bernard JF, Peschanski M, Besson JM (1989) A possible spino (trigemino)ponto-amygdaloid pathway for pain. Neurosci Lett 100:83-88. CrossRef Medline

Cardoso-Cruz H, Lima D, Galhardo V (2013) Impaired spatial memory performance in a rat model of neuropathic pain is associated with reduced hippocampus-prefrontal cortex connectivity. J Neurosci 33:2465-2480. CrossRef Medline

Chaplan SR, Bach FW, Pogrel JW, Chung JM, Yaksh TL (1994) Quantitative assessment of tactile allodynia in the rat paw. J Neurosci Methods 53:5563. CrossRef Medline

Conrad CD, LeDoux JE, Magariños AM, McEwen BS (1999) Repeated restraint stress facilitates fear conditioning independently of causing hippocampal CA3 dendritic atrophy. Behav Neurosci 113:902-913. CrossRef Medline

Coutellier L, Usdin TB (2011) Enhanced long-term fear memory and increased anxiety and depression-like behavior after exposure to an aversive event in mice lacking TIP39 signaling. Behav Brain Res 222:265-269. CrossRef Medline

Coutellier L, Logemann A, Kuo J, Rusnak M, Usdin TB (2011) TIP39 modulates effects of novelty-induced arousal on memory. Genes Brain Behav 10:90-99. CrossRef Medline

Czéh B, Michaelis T, Watanabe T, Frahm J, de Biurrun G, van Kampen M, Bartolomucci A, Fuchs E (2001) Stress-induced changes in cerebral metabolites, hippocampal volume, and cell proliferation are prevented by antidepressant treatment with tianeptine. Proc Natl Acad Sci U S A 98: 12796-12801. CrossRef Medline

Dableh LJ, Yashpal K, Henry JL (2011) Neuropathic pain as a process: reversal of chronification in an animal model. J Pain Res 4:315-323. CrossRef Medline

Duric V, McCarson KE (2006) Persistent pain produces stress-like alterations in hippocampal neurogenesis and gene expression. J Pain 7:544555. CrossRef Medline

Felix-Ortiz AC, Beyeler A, Seo C, Leppla CA, Wildes CP, Tye KM (2013) BLA to vHPC inputs modulate anxiety-related behaviors. Neuron 79: 658-664. CrossRef Medline

Fu Y, Neugebauer V (2008) Differential mechanisms of CRF1 and CRF2 receptor functions in the amygdala in pain-related synaptic facilitation and behavior. J Neurosci 28:3861-3876. CrossRef Medline

Glasper ER, Schoenfeld TJ, Gould E (2012) Adult neurogenesis: optimizing hippocampal function to suit the environment. Behav Brain Res 227:380383. CrossRef Medline

Hanson ND, Owens MJ, Nemeroff CB (2011) Depression, antidepressants, and neurogenesis: a critical reappraisal. Neuropsychopharmacology 36 : 2589-2602. CrossRef Medline

Heine VM, Maslam S, Zareno J, Joëls M, Lucassen PJ (2004) Suppressed proliferation and apoptotic changes in the rat dentate gyrus after acute and chronic stress are reversible. Eur J Neurosci 19:131-144. CrossRef Medline

Hummel M, Lu P, Cummons TA, Whiteside GT (2008) The persistence of a long-term negative affective state following the induction of either acute or chronic pain. Pain 140:436-445. CrossRef Medline

Hunyady B, Krempels K, Harta G, Mezey E (1996) Immunohistochemical signal amplification by catalyzed reporter deposition and its application in double immunostaining. J Histochem Cytochem 44:1353-1362. CrossRef Medline

Ji G, Sun H, Fu Y, Li Z, Pais-Vieira M, Galhardo V, Neugebauer V (2010)
Cognitive impairment in pain through amygdala-driven prefrontal cortical deactivation. J Neurosci 30:5451-5464. CrossRef Medline

Kim SH, Kim SK, Nam EJ, Han SW, Lee SJ (2012) Spatial versus verbal memory impairments in patients with fibromyalgia. Rheumatol Int 32 : 1135-1142. CrossRef Medline

Kirby ED, Friedman AR, Covarrubias D, Ying C, Sun WG, Goosens KA, Sapolsky RM, Kaufer D (2012) Basolateral amygdala regulation of adult hippocampal neurogenesis and fear-related activation of newborn neurons. Mol Psychiatry 17:527-536. CrossRef Medline

Knaster P, Karlsson H, Estlander AM, Kalso E (2012) Psychiatric disorders as assessed with SCID in chronic pain patients: the anxiety disorders precede the onset of pain. Gen Hosp Psychiatry 34:46-52. CrossRef Medline

Kodama D, Ono H, Tanabe M (2011) Increased hippocampal glycine uptake and cognitive dysfunction after peripheral nerve injury. Pain 152: 809-817. CrossRef Medline

Leite-Almeida H, Cerqueira JJ, Wei H, Ribeiro-Costa N, Anjos-Martins H, Sousa N, Pertovaara A, Almeida A (2012) Differential effects of left/right neuropathy on rats' anxiety and cognitive behavior. Pain 153:2218-2225. CrossRef Medline

Li Z, Wang J, Chen L, Zhang M, Wan Y (2013) Basolateral amygdala lesion inhibits the development of pain chronicity in neuropathic pain rats. PLoS One 8:e70921. CrossRef Medline

Ling J, Campbell C, Heffernan TM, Greenough CG (2007) Short-term prospective memory deficits in chronic back pain patients. Psychosom Med 69:144-148. CrossRef Medline

Luis-Delgado OE, Barrot M, Rodeau JL, Ulery PG, Freund-Mercier MJ, Lasbennes $F$ (2006) The transcription factor DeltaFosB is recruited by inflammatory pain. J Neurochem 98:1423-1431. CrossRef Medline

Malmberg AB, Basbaum AI (1998) Partial sciatic nerve injury in the mouse as a model of neuropathic pain: behavioral and neuroanatomical correlates. Pain 76:215-222. CrossRef Medline

McWilliams LA, Cox BJ, Enns MW (2003) Mood and anxiety disorders associated with chronic pain: an examination in a nationally representative sample. Pain 106:127-133. CrossRef Medline

Mosconi T, Kruger L (1996) Fixed-diameter polyethylene cuffs applied to the rat sciatic nerve induce a painful neuropathy: ultrastructural morphometric analysis of axonal alterations. Pain 64:37-57. CrossRef Medline

Mutso AA, Radzicki D, Baliki MN, Huang L, Banisadr G, Centeno MV, Radulovic J, Martina M, Miller RJ, Apkarian AV (2012) Abnormalities in hippocampal functioning with persistent pain. J Neurosci 32:5747-5756. CrossRef Medline

Narita M, Kaneko C, Miyoshi K, Nagumo Y, Kuzumaki N, Nakajima M, Nanjo K, Matsuzawa K, Yamazaki M, Suzuki T (2006) Chronic pain induces anxiety with concomitant changes in opioidergic function in the amygdala. Neuropsychopharmacology 31:739-750. CrossRef Medline

Nestler EJ, Kelz MB, Chen J (1999) DeltaFosB: a molecular mediator of long-term neural and behavioral plasticity. Brain Res 835:10-17. CrossRef Medline

Parent AJ, Beaudet N, Beaudry H, Bergeron J, Bérubé P, Drolet G, Sarret P, Gendron L (2012) Increased anxiety-like behaviors in rats experiencing chronic inflammatory pain. Behav Brain Res 229:160-167. CrossRef Medline

Pedersen LH, Scheel-Krüger J, Blackburn-Munro G (2007) Amygdala GABA-A receptor involvement in mediating sensory-discriminative and affective-motivational pain responses in a rat model of peripheral nerve injury. Pain 127:17-26. CrossRef Medline

Pham K, Nacher J, Hof PR, McEwen BS (2003) Repeated restraint stress suppresses neurogenesis and induces biphasic PSA-NCAM expression in the adult rat dentate gyrus. Eur J Neurosci 17:879-886. CrossRef Medline

Pitcher GM, Ritchie J, Henry JL (1999) Nerve constriction in the rat: model of neuropathic, surgical and central pain. Pain 83:37-46. CrossRef Medline

Plümpe T, Ehninger D, Steiner B, Klempin F, Jessberger S, Brandt M, Römer B, Rodriguez GR, Kronenberg G, Kempermann G (2006) Variability of doublecortin-associated dendrite maturation in adult hippocampal neurogenesis is independent of the regulation of precursor cell proliferation. BMC Neurosci 7:77. CrossRef Medline

Radat F, Margot-Duclot A, Attal N (2013) Psychiatric co-morbidities in patients with chronic peripheral neuropathic pain: a multicentre cohort study. Eur J Pain 17:1547-1557. CrossRef Medline

Rainnie DG, Bergeron R, Sajdyk TJ, Patil M, Gehlert DR, Shekhar A (2004) 
Corticotrophin releasing factor-induced synaptic plasticity in the amygdala translates stress into emotional disorders. J Neurosci 24:34713479. CrossRef Medline

Ren W, Neugebauer V (2010) Pain-related increase of excitatory transmission and decrease of inhibitory transmission in the central nucleus of the amygdala are mediated by mGluR1. Mol Pain 6:93. CrossRef Medline

Rouwette T, Vanelderen P, de Reus M, Loohuis NO, Giele J, van Egmond J, Scheenen W, Scheffer GJ, Roubos E, Vissers K, Kozicz T (2012) Experimental neuropathy increases limbic forebrain CRF. Eur J Pain 16:61-71. CrossRef Medline

Samuels BA, Hen R (2011) Neurogenesis and affective disorders. Eur J Neurosci 33:1152-1159. CrossRef Medline

Sarhan M, Pawlowski SA, Barthas F, Yalcin I, Kaufling J, Dardente H, Zachariou V, Dileone RJ, Barrot M, Veinante P (2013) BDNF parabrachioamygdaloid pathway in morphine-induced analgesia. Int J Neuropsychopharmacol 16:1649-1660. CrossRef Medline

Schoenfeld TJ, Gould E (2012) Stress, stress hormones, and adult neurogenesis. Exp Neurol 233:12-21. CrossRef Medline

Seltzer Z, Dubner R, Shir Y (1990) A novel behavioral model of neuropathic pain disorders produced in rats by partial sciatic nerve injury. Pain 43:205-218.

Terada M, Kuzumaki N, Hareyama N, Imai S, Niikura K, Narita M, Yamazaki
M, Suzuki T, Narita M (2008) Suppression of enriched environmentinduced neurogenesis in a rodent model of neuropathic pain. Neurosci Lett 440:314-318. CrossRef Medline

Tóth ZE, Mezey E (2007) Simultaneous visualization of multiple antigens with tyramide signal amplification using antibodies from the same species. J Histochem Cytochem 55:545-554. CrossRef Medline

Urban R, Scherrer G, Goulding EH, Tecott LH, Basbaum AI (2011) Behavioral indices of ongoing pain are largely unchanged in male mice with tissue or nerve injury-induced mechanical hypersensitivity. Pain 152: 990-1000. CrossRef Medline

Vacca V, Marinelli S, Luvisetto S, Povone F (2013) Botulinum toxin A increases analgesic effects of morphine, counters development of morphine tolerance, and modulates glia activation and $\mu$ opioid receptor expression in neuropathic mice. Brain Behav Immun 32:40-50. CrossRef Medline

Yalcin I, Bohren Y, Waltisperger E, Sage-Ciocca D, Yin JC, Freund-Mercier MJ, Barrot M (2011) A time-dependent history of mood disorders in a murine model of neuropathic pain. Biol Psychiatry 70:946-953. CrossRef Medline

Zhao Y, Wang Z, Dai J, Chen L, Huang Y, Zhan Z (2012) Beneficial effects of benzodiazepine diazepam on chronic stress-induced impairment of hippocampal structural plasticity and depression-like behavior in mice. Behav Brain Res 228:339-350. CrossRef Medline 